SÁNCHEZ-OSTIZ, Pablo "En respuesta a Juan Pablo Montiel.

Una réplica a su recensión de Fundamentos de Política criminal"

Polít. crim. Vol. 9, No 17 (Julio 2014), Doc. 1, pp. 270 - 275.

[http://www.politicacriminal.cl/Vol_09/n_17/Vol9N17D1.pdf]

\title{
En respuesta a Juan Pablo Montiel. Una réplica a su recensión de Fundamentos de Política criminal
}

\author{
Pablo Sánchez-Ostiz \\ Universidad de Navarra \\ pablosostiz@unav.es
}

En el número 16, se publicó una recensión, obra de Juan Pablo Montiel ("En busca de una teoría de los principios jurídico-penales", Política Criminal Vol. 8, núm. 16, Diciembre de 2013, pp. 612-621), a la monografía Fundamentos de Política criminal, de la que soy autor. Dicha recensión ofrece un buen resumen de algunos planteamientos del libro, y centra su crítica sobre todo en los de orden metodológico. Y puesto que hace reflexionar, me brinda la oportunidad de entrar en diálogo científico con el recensionador. He de agradecer al profesor Montiel sus observaciones: con el rigor que le caracterizan, me han permitido descubrir algunos aspectos en los que mi exposición requiere más claridad. Me centraré en la parte crítica de lo expuesto por Montiel, sin omitir que su trabajo es algo más que una recensión: es también una exposición sobre los principios de la Política criminal, su operatividad en la praxis cotidiana..., y todo con referencias bibliográficas que avalan la relevancia de los temas tratados y las opiniones por él expuestas. Cabe esperar que lo que ha sido publicado como recensión dé lugar a un artículo, pues su trabajo casi lo es.

I.

Comienzo mostrando mi coincidencia con Montiel en lo que se refiere a la polisemia y frecuencia de uso de los principios: apenas hay tema dogmático en la actualidad en el que no se recurra a un principio. Pero así sucede también en la Jurisprudencia, y en las Exposiciones de Motivos de los proyectos de ley... Coincidimos en que tan frecuente recurso a los principios resulta poco fructífero si no se aclara antes a qué nos referimos con tal concepto $-\mathrm{y}$ añado: también con los de regla, subprincipio...- y con los postulados de cada uno de ellos. Aquí la opinión de Montiel resulta drástica, al sentar como condición para formular una teoría general de los principios que se logre responder a las cuestiones claves de orden conceptual ("v.gr. el concepto de los principios y su interacción con las reglas jurídico-penales; la función en el razonamiento juridicial y legislativo") y jurídicopolítico ("v.gr. la legitimación política de su uso"). Como bien señala, "que podamos tener una teoría de los principios satisfactoria en el Derecho penal depende de que estas limitaciones sean superadas" (p. 614).

En esa dirección va el cap. II de Fundamentos de Política criminal, como presupuestos metodológicos de la obra y que aspira a definir los conceptos de principio, subprincipio, regla, excepción y metarregla, como herramientas conceptuales claves. Y por aquí se dirige también la crítica vertida por Montiel. Ciertamente puede dudarse de si he logrado una conceptualización acabada (p. 614), a la vista de que mi contribución no deja de ser la propia de un extraño que se suma al debate - que ya va siendo largo y extenso- sobre el concepto y virtualidad de los principios. Pero no era mi propósito reproducir una larga serie 
SÁNCHEZ-OSTIZ, Pablo "En respuesta a Juan Pablo Montiel.

Una réplica a su recensión de Fundamentos de Política criminal"

de argumentos, como tampoco no lo fue entrar al debate entre los protagonistas de la discusión (Hart, Dworkin, Alexy), más allá de lo imprescindible. Se trataba más bien de explicar cómo operamos realmente en la Política criminal. En ese proceso, se hace necesario levantar la mirada sobre manidos tópicos o afirmaciones generales, y aclarar cuáles son los instrumentos necesarios para entender los principios. De ahí que la exposición no haya seguido por derroteros (nota 14) que posiblemente me alejarían del propósito inicial.

Se afirma además que en Fundamentos no se aborda el análisis de algunas clases de principios, como las rationes legis y los principios institucionales, para centrarse más bien en una teoría de los principios limitadores del ius puniendi (pp. 615-616). Y así es. La obra reseñada no aborda todos los temas posibles dentro del mundo de los principios, sino sólo aquellos que sirven para explicar los límites al ius puniendi. Deja abierta así otras cuestiones: la señalada por Montiel, como también la no menos importante de si los tres principios son operativos en otras ramas del Derecho, algo que dejo solamente apuntado y no desarrollado (Fundamentos, pp. 94-96, párr. 7).

El propósito inicial del libro era racionalizar el modo de proceder de la Política criminal. Para lo cual adopté de partida un método inductivo: desde los concretos enunciados reconocidos en la praxis de la Política criminal (nemo tenetur..., ne bis in idem, irretroactividad, taxatividad, abolición de la pena de muerte...) la indagación se va remontando hacia los principios. Esto explica que la parte sistemática (caps. 4-6) resulte poco "original", en el sentido de que ofrece una descripción de abundantes reglas operativas generalmente reconocidas. Lo "original" -si es que se puede emplear dicho calificativo- reside en haberlas sistematizado y también en haberlas puesto en relación con sus respectivas excepciones (porque la argumentación de decisiones jurídicas se construye para casos, pero admiten excepciones): y tan importantes resultan unas como otras. Original es también -o al menos inusual- la exposición de los tres principios (socialidad, legalidad y respeto de la dignidad) que conforman el entramado de las variadas y mudables decisiones. Ciertamente, como bien ha percibido el profesor Montiel, no se presenta aquí una teoría acabada de los principios, pero tampoco es posible enfrentarse a la polisemia reinante y lograr aportar un poco de luz y sistema en el proceloso mundo de los principios, sin contar con un mínimo de fundamentación. Eso sí se pretende en Fundamentos de Política criminal.

II.

Tras resumir el contenido de la obra, la recensión de Montiel se centra críticamente en algunos aspectos metodológicos (pp. 616-618). Mi réplica se dirige, sobre todo, a estas objeciones.

En primer lugar, se critica (p. 619) que -en mi exposición, Fundamentos, pp. 59 y ss.- "los principios político-criminales son inoperantes para su aplicación directa y que además tampoco son capaces de brindar soluciones uniformes a los casos". Por tanto, "respecto al juez lo limitante no serían los principios sino, en realidad, las reglas que se derivan de ellos"; los principios se caracterizan "por carecer de condiciones de aplicación, esto es, por 
Polít. crim. Vol. 9, No 17 (Julio 2014), Doc. 1, pp. 270 - 275.

[http://www.politicacriminal.cl/Vol_09/n_17/Vol9N17D1.pdf]

no poseer un supuesto de hecho", de modo que el manejo de principios acabaría estando totalmente independizado de un sustrato fáctico concreto, es decir, el carácter prescriptivo de un principio no estaría sujeto a ninguna situación fáctica concreta y, por ende, podría ser "extensible a cualesquiera constelaciones" de casos, de modo que perderían referencia al problema y no podríamos saber de qué manera limitan una decisión político-criminal; así "[1]os principios devendrían en realidades puramente etéreas".

Ciertamente los principios no están dotados de una gran capacidad de limitación, si por tal se entiende que se imponen con una implacable fuerza de convicción. Me temo que no es eso lo propio de los enunciados normativos. Lo propio de todas las normas es que su vigencia y eficacia se asegura mediante otras normas, que son los instrumentos idóneos para ello. No es posible un aseguramiento cognitivo de los mensajes normativos, sino que procede una garantía normativa a su vez. Y tratándose de decisiones (Fundamentos, pp. 3642) de Política criminal (leyes, sentencias, actos administrativos...), lo idóneo es aportar motivos de convencimiento, es decir, razones de viabilidad y plausibilidad de las decisiones. De ahí también la importancia de respetar de entrada los condicionantes de la lógica, si es que queremos hacer viable una decisión (Fundamentos, p. 44); como también de observar cierta coherencia material con enunciados más amplios y previos, como son los principios (Fundamentos, pp. 123-126). En este sentido, puede afirmarse que la fuerza limitadora de los principios es la que el agente de la argumentación jurídica les reconozca: incluso se puede afirmar que la capacidad limitadora reside en los agentes de la argumentación, como sujetos del discurso, y no en afirmaciones que se impongan por sí mismas, axiomáticas, autoevidentes. Los principios proporcionan una elevada carga de «buenas razones» para adoptar y asumir decisiones en materia de Política criminal. Que se hallen previstos expresamente en los textos constitucionales, o en declaraciones de derechos, o en precedentes judiciales..., ayuda a reconocerles fuerza de convicción, en la medida en que se le atribuye a la respectiva instancia de promulgación; pero de hecho nos basamos en esas razones en la medida en que no sólo se han asumido en los textos y declaraciones, sino sobre todo porque expresan un patrimonio común de ideas: los principios. Que estos carezcan del presupuesto jurídico de que vienen dotadas otras normas no me parece un punto débil, sino una mera descripción de su estatuto normativo. Es decir, que dicha carencia de presupuesto no me parece una "carencia": implica que no abocan a soluciones únicas, sino que contribuyen a la adopción de decisiones, que son las concretas reglas. Su carácter "etéreo" es el propio de una norma que es, no sólo general, sino abierta a múltiples supuestos de hecho, los de las respectivas reglas y excepciones. Es algo que viene dado por la propia entidad de esa clase de normas. Su capacidad limitadora puede resultar escasa por difusa; sin embargo, aquí está precisamente su fuerza: que no se imponen por sí mismos (porque, como normas, no se aseguran mediante instrumentos cognitivos, sino normativos), sino a través de su "des-abstracción" y sucesiva concreción en reglas (y excepciones). Con todo, el principio sí está dotado de cierta fuerza de convicción por sí mismo, y es la que deriva de la autocontradicción en que incurre quien niegue el contenido de un principio (Fundamentos, p. 72, párr. 5).

Ciertamente, el propio Montiel eleva la cuestión a otra más general y amplia ("¿son realmente capaces los principios jurídicos de limitar el Derecho penal?”, p. 619), y adelanta su respuesta -más bien negativa. Si por limitación se entiende que ofrecen un 
SÁNCHEZ-OSTIZ, Pablo "En respuesta a Juan Pablo Montiel.

Una réplica a su recensión de Fundamentos de Política criminal"

blindaje no evitable, entonces hay que responder negativamente: los principios carecen de una gran fuerza de limitación. Pero si por limitación se entiende que proporcionan razones para la decisión, entonces hay que convenir que se trata de buenas razones, y que están dotados de gran capacidad de limitación, porque dejan en evidencia aquellas decisiones que resulten poco fundadas, débiles o inconsistentes.

En segundo lugar, se critica la noción de las metarreglas (p. 620): "no alcanza a quedar demasiado claro cuáles son los beneficios de introducir la noción"; "son más los problemas que las bondades que trae"; "solamente conducen a poner en tela de juicio una idea que parece central en la obra que analizamos: básicamente que en los principios se da una dimensión de peso y no de validez"; acaban por ser "un criterio material ubicado "por encima" de los principios", de modo que harían perder el carácter "principial" de los principios. Considera, además, que las metarreglas son innecesarias en el sistema propuesto en Fundamentos, hasta el punto de que entrarían en contradicción con uno de sus puntos de partida, como es que los principios no abocan a decisiones unitarias y cerradas, sino que dan entrada a diversas consideraciones a través de la argumentación en el caso concreto: "las metarreglas fijarían de antemano cómo se resuelven los conflictos de principios, sepultando cualquier valor de la dimensión "peso" de los principios." "En definitiva, ... las metarreglas darían criterios a priori de decisión en detrimento de las particularidades del caso concreto.".

Se trata de objeciones sobre la figura misma de las metarreglas. He de reconocer, como Montiel ha visto, que se trata de un instrumento poco convencional. Ciertamente la discusión habitual se centra en las figuras de principio y regla. En mi exposición me vi obligado a idear la denominación de subprincipio, para agrupar diversas reglas que responden a una misma operación de ponderación entre dos principios: a pesar de que agrupan reglas, no di con una denominación mejor, que no evocara su carácter de principio, sino que conectara con el de regla, pues eso es lo que hacen tales enunciados: aunar reglas en función de ponderaciones entre principios. Pero no podían denominarse metarreglas, pues esta expresión denota que son reglas sobre el funcionamiento de reglas, lo cual no es el caso, En cambio, la expresión "metarregla" sí puede aplicarse a otro grupo de enunciados, los referidos a la operatividad de las reglas. En efecto, en el estudio pormenorizado de decisiones (reglas y excepciones) me parece percibir que intervienen criterios de decisión de segundo orden, que no son los propios principios (poco operativos per se), ni tampoco reglas (se trata de arbitrar entre ellas). Se trataría más bien de algunas "normas de funcionamiento" o -si se me permite- "instrucciones de uso" de las reglas. De ahí la expresión. Se trata de criterios operativos sobre el modo de proceder con las reglas (Fundamentos, p. 79, párr. 1). Con otras palabras, que proporcionan criterios de preferencia o prevalencia entre reglas. Ya cumplen dicha función no pocos enunciados, como los de lex superior derogat inferiori, lex specialis derogat generali, lex praevia derogat posteriori..., que ponen de manifiesto cómo las decisiones de Política criminal deben respetar al menos algunos condicionantes de jerarquía, preferencia, validez... Por tanto, no me parece que prescindir de tales condicionantes sea poco beneficioso. Al contrario, puede servir para evidenciar el orden del modo de proceder habitual en un discurso racional; y la Política criminal aspira a serlo. 
Polít. crim. Vol. 9, No 17 (Julio 2014), Doc. 1, pp. 270 - 275.

[http://www.politicacriminal.cl/Vol_09/n_17/Vol9N17D1.pdf]

Pero se trata además de convencer de que en efecto las tres metarreglas que yo propongo (Fundamentos, pp. 80-83, párr. 2) sean tan claras como esos enunciados que acabo de citar. En este punto no se trata de postulados tan evidentes, pero no por eso son menos relevantes. Obsérvese que la metarregla de "compensación entre principios" (que la solución adoptada en un principio no es definitiva, sino que queda abierta a nuevas soluciones; Fundamentos, p. 82) es una forma de hablar de la apertura a la argumentación de nuevas decisiones para otros casos y situaciones. Por tanto, es muestra de que la clave está en adoptar una argumentación racional que conduzca a decisiones plausibles; lo cual pone de manifiesto cómo las decisiones no se hallan predeterminadas por unas metarreglas que fijarían de antemano la solución a concretos casos, desplazando la dimensión "peso" de los principios. Al contrario. Puesto que los principios tienen relevancia (digamos "gravedad"), hay que decidir cuál, cómo y cuándo entra en juego para adoptar una decisión. No establecen criterios a priori, sino reglas de operatividad no cerrada. Así lo muestra por lo demás la "metarregla de la validez condicionada" que acabamos de citar; pero también la de "no exclusividad" (Fundamentos, p. 81). Es decir, me parece que son muestra de cómo los principios no carecen de dimensión de peso, sino de que hay que hacer valer esa "gravedad" en el concreto caso y decisión. Su función es instrumental y no prejuzga una decisión, sino que da entrada a los tres principios en juego. Por tanto, en definitiva, no pueden tener el carácter de "criterio material ubicado "por encima" de los principios", como - por ejemplo- tampoco las normas procesales están por encima de las normas sustantivas del caso; y no por ello pasan a ser de tal relevancia que desplacen a las normas que aplican, ni sean tan accesorias que resulten prescindibles. Y razones de peso son las que obran también en la metarregla de la "prioridad condicionada entre principios" (Fundamentos, p. 80), en virtud de la cual esa cierta jerarquía entre principios conduce a una paralela carga de argumentación: no es la misma la entidad del principio de dignidad que el de seguridad en la vida social, pues el primero plasma de manera más intensa lo propio de lo humano, la dignidad, frente al segundo, pues la coexistencia o socialidad que le sirve de base no realiza plenamente al ser humano (Fundamentos, pp. 96-116).

Es en este punto donde - a mi parecer- las críticas de Montiel sobre las metarreglas apuntan a una cuestión clave. Y es la de los tres concretos principios. ¿Por qué esos tres y no otros? ¿Por qué tres y no más? Que sean esos tres es algo a lo que quien escribió Fundamentos de Política criminal llegó a través de un estudio inductivo y sistemático de concretas reglas y excepciones operativas. Todas ellas, y algunas más - ¿por qué no?-, como decisiones que son, se podrían ir agrupando como expresión de criterios generalizados y asumidos, como los de legalidad, culpabilidad, subsidiariedad y otros. Los cuales, a su vez, presentan sus puntos de contacto y elementos propios. Es donde aparecen los tres principios (seguridad en la vida social, legalidad y respeto de la dignidad) sobre la base de otros tantos radicales humanos, como son la coexistencia, la libertad y la dignidad personales.

$* * *$

La recensión de J.P. Montiel me ha brindado la oportunidad de matizar o precisar algunos aspectos de los Fundamentos de Política criminal. Su recensión es una muestra de lo propio del diálogo académico. Como expresé en sus primeras líneas (Fundamentos, p. 18), dicha obra aspiraba a suscitar el debate científico, y con ello a poner de manifiesto el 
SÁNCHEZ-OSTIZ, Pablo "En respuesta a Juan Pablo Montiel.

Una réplica a su recensión de Fundamentos de Política criminal"

carácter político de nuestra actividad: política, en el sentido de praxis colectiva, de la polis, cuyas decisiones frente a las conductas humanas delictivas aspiramos a informar. 